\title{
Demand for food as driver for plant sink development
}

Frank Ludewig $^{1^{*}}$ and Uwe Sonnewald ${ }^{1}$

${ }^{1}$ Division of Biochemistry, Department of Biology, Friedrich-Alexander University Erlangen-Nuremberg, Staudtstraße 5, D-91058 Erlangen, Germany

* Corresponding author: Correspondence and requests for materials should be addressed to Frank Ludewig (phone: +49 913185 28844; E-mail: frank.ludewig@fau.de)

\section{Summary}

Starting with the first humans settling down to build their lives on agriculture and stock breeding, the development of food and feed became tremendously important. With increasing population, in particular boosted by industrialization, the need for more food rose further. One way to cope with the needs of people was to open up new and optimize already existing resources like the introduction of potato into the European population's diet and the development of grasses to high-yielding cereals, respectively. The process of plant improvement is still ongoing. Nowadays, yield enhancement is still an important breeding aim for several plant species as world population further increases, especially in less developed regions. However, in addition to quantity improvement, food quality is in the focus to prevent human malnutrition and resulting diseases or early death.

In this review we will give a brief historical overview on how plants were developed to nourish the population and will discuss more recent approaches to secure sufficient food production.

\section{Keywords}

Food, source, sink, carbon, allocation

\section{Introduction}

The intensive production of food for an already high and further growing population has negative impact on the environment (Tilman et al., 2002, 2001). Especially meat 
production reduces the energy efficiency strongly, i.e., the consumption of meat vs. plant products clearly is accompanied by an increase in energy waste (Pimentel and Pimentel, 2003). In addition, it increases the production of greenhouse gases by methane production of cattle (EPA, 2010) and reduces biodiversity by forest grubbing to create grazing land and, by that, could destroy endangered ecosystems (Kaimowitz et al., 2004). These negative environmental consequences can be relieved only by abstaining from excess meat consumption - a socio-political issue and/or by enhancing the per hectare yield of food crops without increasing the consumption of resources (Figure 1).

\section{Food}

Substances called 'food' are consumed by humans to provide nutritional support for their body. It is usually of plant or animal, in rare cases of fungal or bacterial origin. To raise animals, these have to be fed with feed of either animal or plant origin. Thus, in a sense almost all food originates from plant sources, in particular of a process known as photosynthesis. Organic matter production by the process of chemosynthesis, in contrast, might be of local importance, but is almost neglectible on a global scale (Cullen, 2001).

Food can be consumed directly as vegetable like cucumber, fruit like apple, seed like corn or leaf like lettuce. In other cases, food has to be processed to yield an edible product, (i) by cooking, e.g. potato or rice, (ii) by milling to produce flour, e.g. of wheat, potato or cassava, (iii) by extraction to yield e.g. juice, (iv) by salting, curing, pickling, drying, fermenting or smoking. The latter manufacturing techniques were developed to preserve food for a longer period of time.

Indirect consumption of food originating from plants are animal products like milk and its processed variants, e.g. curd or cheese, eggs of birds or honey produced by bees. In addition to animal products several parts of the animal itself, summarized as meat, is a source of food.

\section{Sink}

Sink organs of plants are net importers of photosynthesis products (Ho, 1988), i.e., these organs are unable to produce sufficient photosynthate to sustain metabolism and growth without the import of carbon in form of sugars or related substances. Other plant organs, essentially mature leaves, are net exporters of photosynthate, 
i.e., they produce more photosynthesis products than needed to maintain their own metabolism. These so-called source leaves supply sink organs with carbon and enable growth and development of sinks as well as accumulation of storage compounds in sinks. The allocation of substances other than carbon, e.g. nitrogen or phosphorus, within the plant is also of importance for plant growth, and in case of nitrogen, also for the storage of protein (Zhang et al., 2015; Sinclair and de Wit, 1976).

All below-ground organs are carbon sinks during plant growth as they obviously cannot perform photosynthesis. Moreover, immature leaves as well as other aboveground plant organs like flowers, petioles, stems or seeds are sinks. Amongst the above-mentioned sinks, some switch to source organs during plant development. Upon maturation of leaves, they undergo a transition from sink to source organs (Turgeon, 1989). In addition, storage sinks like seeds, tubers, roots and stems convert from sinks to sources during development. For this, storage compounds built up in their sink phase are remobilized to be exported to drive e.g. germination. Typically, this conversion occurs after death or independently of the mother plant after a dormancy period. An interesting exception is the tropical crop cassava. When cassava experiences extreme drought conditions, i.e., at the onset of and during the dry season, it drops almost all leaves to save water. When conditions are more favorable again, i.e., when rainy season starts, storage roots and stems switch to source organs intermediately to enable generation of new leaves. Upon maturation, these newly emerged leaves become source organs again, and storage roots and stems switch back to the sink status (El-Sharkawy, 2004, Hahn et al., 1992).

\section{Food - sink relations}

In general, plants (and also organisms of other kingdoms) evolved two contrasting strategies to secure survival of the next 'generation', they either produce a huge number of individual offspring, a strategy e.g. Arabidopsis thaliana follows, or they produce only a small number of offspring (Gnan et al., 2014). These few, however, are usually well equipped with energy stores that support the next 'generation' to establish and to survive. Lots of different shades of grey between these black and white strategies evolved for different species. 'Generations' in this context can also be clones like potato tubers which are genetically identical with the mother plant, 
however, are produced by the mother plant to ensure existence in the next growing period.

Even when plants evolved the former strategy, they supply their offspring, usually seeds, with storage compounds which can be degraded during germination and used to establish a seedling capable of photosynthesis.

Moreover, plants enable the spread of their offspring by different strategies. In the context of sinks, the most interesting one put into effect is the development of the fruit. Here, seeds are embedded in the fruit which is formed from the ovary after flowering and filled with sugars. These fruits attract animals which eat them and later deposit them again, thus ensure spread of the offspring.

Early humans survived by hunting animals and gathering edible plant parts. When humans settled down to practice agriculture, they started domestication of both, animals and plants. For that, they first chose animal and plant species they wanted to rear and grow, respectively. Later, they started to optimize the organisms for their needs.

Very often, the most nutritious and edible parts of plants are the sinks as they are equipped with storage products to enable a good start for the next 'generation' of plants or attract animals for spreading. These storage compounds like starch, sugar, oil/fat and proteins are also good for human nutrition, and thus domestication (and later breeding) concentrated on enlarging sinks initially just by picking individual plants with the biggest sinks from the pool to further grow them.

\section{Milestones in food improvement and plant breeding}

In the early phase of cereal cultivation by selection the gene pool of wild relatives of modern crops was shaped, and during this process the size of individual seeds and of the spike of grasses was increased leading to the development of early cereals like einkorn (Triticum monococcum). Modern wheat (Triticum aestivum) originated from either einkorn or Triticum urartu hybridized with Aegilops speltoides to yield the allotetraploid Triticum turgidum, which, in turn, hybridized with Aegilops tauschii to yield the allohexaploid Triticum aestivum, which was since cultivated (The International Wheat Genome Sequencing Consortium (IWGSC, 2014)). Rise of the ploidy level from diploid to - in this case - hexaploid is often found when comparing ancestral varieties with modern ones, and it is often correlated with an increase in yield. Potato is another example for a positive correlation of ploidy level and yield 
when comparing primary with modern varieties. Such an increase in ploidy, however, is not a prerequisite for a high yielding offspring of an ancestral crop. The food crop with the highest acreage and yield world-wide, corn (Zea mays), is diploid and emerged from teosinte, also a diploid organism (Doebley, 2004; Beadle, 1980). Common to the two cereal examples is the enlargement of seeds and a less fragile rachis enabling a higher and more efficient harvest and threshing of seeds. In contrast, for non-domesticated forms a fragile rachis is an advantage as to the more efficient shattering (Li and Gill, 2006).

Breeding by positive and negative selection was state of the art in agriculture when the era of industrialization started in the mid to late $18^{\text {th }}$ century (Breseghello, 2013). In the course of industrialization, more and more people moved into expanding cities as they were needed as workers, and thus were dependent on someone else to produce their food. Alternatively, worker families produced their own food in small gardens rather than on fields. In both cases an increase of yield per hectare had to be established to nourish the growing population. Because yield of cereals was not able to cope with the needs, a new crop to Europe, the potato started a triumphal procession. Potato had several advantages over cereals that days, it was more nutritious, easier to grow, no milling was necessary, and - most importantly - it had and still has a higher yield per hectare than cereals (http://faostat3.fao.org/home/E). These advantages led to a complete dependance of mainly underprivileged workers and their families on potato, e.g. one third of the population in Ireland was reliant on potato as source of calories. In this situation, in the 1840s, the disease potato blight caused by the oomycete Phytophthora infestans hit Europe. It led to consecutive entire harvest losses and caused a great famine in Europe, especially in Ireland. Irish population fell by more than $20 \%$ because millions of people died or emigrated from Ireland (Kinealy, 1994).

With the discovery of 'heritable traits' by Gregor Mendel (1866), the foundation was laid for educated breeding by crossing, i.e., for combinatorial breeding, although spontaneous and also deliberate crosses occurred and might have been done, respectively, prior to the discovery of the underlying mechanisms. Two varieties (or genotypes) of one species are crossed to yield second generation offspring with stable combined desirable properties.

An enhancement of this approach was to generate hybrids, first generation offspring of two crossed varieties. At the beginning of the $20^{\text {th }}$ century, heterosis has been 
described as the 'tendency of progeny of a specific cross to outperform both parents' (Shull, 1908), i.e., hybrids with higher yield than stable varieties could be produced. Nowadays, several crops are grown as hybrids because of their superior yield, amongst them sugar beet, canola and corn. With the development of the maternally inherited so-called cytoplasmic male sterility (CMS) technique in maize resulting in the production of sterile pollen, laborious detasseling to prevent self-pollination was not necessary anymore (Schnable and Wise, 1998). The development of hybrid maize and its exploitation is one aspect of the substantial increase in crop productivity in the 1960s nowadays referred to as 'Green Revolution' (Everson and Golin, 2003). Another important aspect was the development and subsequent introduction to agriculture of short stray cereals with low gibberrelic acid (GA) concentration (Peng et al., 1999). These cereals had two major advantages over their ancestors. First, plants were able to use more photosynthesis products to generate harvestable organs instead of investing it into long stems, and second, in addition, the self-support of culms was increased leading to superior yield especially after periods of bad weather, when long straw variants tend to be prone to water-logging. Moreover, the supply of crop plants with minerals was increased as artificial fertilizer had been developed in the meantime, and its positive impact on yield (Stewart et al., 2005) was exploited accordingly.

The optimization process of allocation of photosynthate and other substances between plant organs is not yet finished. In contrast, source and sink capacities are far from being optimized for several given environmental situations.

One important downside of the intensification of agriculture is the negative impact on biodiversity. (i) More land was needed for the economic production of more food. This land often had not been used for agriculture before but as refugium (Verhoeven and Setter, 2010) from (ii) massive chemical application which could be better applied to bigger monocultures than to smaller lots of land characteristic for farms prior to intensification of agriculture. (iii) Breeders concentrated on a few varieties that had been chosen during early domestication of only few crops particularly suitable for use in intensive agriculture. Possible sources for important traits like resistances against pathogens might have gone extinct already (Tanksley and McCouch, 1997).

\section{Modern methods for food improvement}


Because of the growing world population (United Nations, 2015), the ever-enhancing per capita consumption of calories (http:/faostat3.fao.org/home/E) and the simultaneous erosion of arable land (Pimentel and Burgess, 2013), there is an increasing need for improvement of plant yield. From a plant physiologist's perspective, a combined strategy might be followed to close this gap in supply: development of yield-improved plants by transgenesis, genome editing and breeding. These approaches should be followed simultaneously, i.e., not only independently but also combined such that knowledge and principles gained from one approach can be incorporated into the others, e.g., knowledge gained from a transgenic plant with superior yield caused by over-expression of a certain gene might be translated into markers associated with high expression of the respective gene and used for S.M.A.R.T. (selection with markers and advanced reproductive technologies) breeding, also referred to as precision breeding (Davis et al., 1997). Moreover, genome editing methods have been developed in recent years that should and certainly will be exploited in plant breeding and biotechnology. In a recent review (Cardi, 2016), genome editing has been described to include 'a set of techniques that allow to edit, delete, replace or insert, in a targeted site, specific genomic sequences of interest'. One advantage of these newly developed methods is that genetic engineering of plants can be performed in a targeted manner. Prior to the invention of methods allowing the introduction of sequence-specific DNA double strand breaks by meganucleases (Daboussi et al., 2015), zinc finger nucleases (ZFNs; Petolino, 2015; Kim et al., 1996), transcription activator-like effector nucleases (TALENs; Christian et al., 2010; Boch et al., 2009) or clustered regular interspaced short palindromic repeats (CRISPR)-associated nucleases (CRIPR/Cas9; Kumar and Jain, 2015; Bortesi and Fischer, 2014; Jinek et al., 2012), now summarized as 'genome editing', higher plants were recalcitrant to gene targeting because of their very low frequency of homologous recombination. Consequently, transgenic plants including mutants had to be produced by random insertion of T-DNA into the genome. According to the JRC Scientific and Technical Report, crops resulting from most of the genome editing techniques cannot be distinguished from conventionally bred crops and detection is therefore not possible (Lusser et al., 2011). In such cases, it has been suggested to treat genome-edited plants as non-GM plants. Moreover, eventually genome editing could lead to more social acceptance of plant breeding (Araki and Ishii, 2015; Huang et al., 2016), especially in Europe. 
With combinatorial exploitation of this recently developed set of techniques, urgently needed food improvement might be reached faster than expected.

\section{Carbon allocation between source and sink}

How to improve yield of a crop? To approach this question, turning it around is helpful: What are the obstacles for high yield? The answers to this question are diverse. To name a few, (i) adverse environmental conditions (heat stress, cold, water-logging or drought), (ii) bad agronomy (insufficient fertilizer, inappropriate soil cultivation) or (iii) all kinds of diseases. Common to these examples with negative impact on yield is that they are environmental issues. To minimize impact of these obstacles and thus to stabilize yield, several measures are already conducted, e.g. field covers, artificial irrigation, fertilizer distribution, spraying of fungicides, herbicides and insecticides or growing pathogen-resistant plants. Less considered as negative impact on yield are plant intrinsic issues, e.g. the allocation of nutrients within the plant. Here, we focus on the allocation of carbon between source and sink tissue.

During different growth phases, plants have different needs with respect to finally giving an optimal yield (Figure 2). Shortly after germination, a plant should build up leaves and roots to ensure photosynthesis and uptake of minerals, respectively, for optimal growth (Figure $2 \mathrm{~A}$ ). In the generative growth phase (Figure $2 \mathrm{~B}$ ), plants fill their sinks to enable a good start for the next generation. Accordingly, most assimilates are used for this purpose. In case of pathogen attack (Figure $2 \mathrm{C}$ ), assimilates have to be invested in defending the plant against pathogens and thus miss in optimal sink filling.

Plants evolved respective developmental and defence programs according to their needs. However, crops are usually not grown in the challenging environment these developmental and defence programs had evolved in, but are typically pampered, e.g. by chemicals protecting them against all kinds of pathogens, to yield a better harvest. In these conditions, the potential for higher yield might be hampered by restrictive intrinsic developmental programs, e.g. a short sink filling phase, or by keeping up unnecessary defence pathways. One way to overcome such limitations is to increase both, source and sink capacities eventually resulting in an increased flux of carbon towards sinks and thus in plants with higher yield. As in different growth phases a switch between source- and sink-limitation of yield is likely, increasing the capacity of both might lead to a better adapted growth of plants finally leading to 
higher yield. An example for a successful deregulation of source and sink limitations are triple-transgenic potato plants with increased source and sink capacities (Jonik et al., 2012). The glucose 6-phosphate/phosphate translocator (GPT) importing carbon skeletons into amyloplasts (Kammerer et al., 1998) and the adenylate translocator (NTT) importing energy into amyloplasts (Kampfenkel et al., 1995) were overexpressed under control of the tuber-specific B33 patatin promoter (Rocha-Sosa et al., 1989). Higher activities of these two metabolite transporters had been shown earlier to enhance sink strength and tuber starch yield, whereas, individual overexpression of either transporter did not (Zhang et al., 2008). In addition to increasing sink capacity, source capacity was enhanced by stimulating leaf sucrose formation at the expense of leaf starch formation mediated by two different approaches: (i) ADP glucose pyrophosphorylase was down-regulated in leaves by an antisense approach or (ii) a soluble pyrophosphatase was over-expressed in the cytosol of mesophyll cells. The resulting triple-transgenic potato plants showed a doubling of tuber starch yield (Jonik et al., 2012). Other approaches with the potential to enhance source or sink capacities had been either carried out already or could be envisaged promising (Figure 3). However, apart from the above-mentioned approach (Jonik et al., 2012), a simultaneous increase of source and sink capacities has not been reported on thus far.

To enhance source capacity, the most obvious approach would be to increase photosynthesis. A large-scale visionary approach is to equip so-called C3 plants with the more efficient $\mathrm{C} 4$ photosynthesis. Invention of $\mathrm{C} 4$ photosynthesis occurred independently several times in evolution (Sage et al., 2011) and modeling the transition from C3 to $\mathrm{C} 4$ photosynthesis indicated that every necessary step offers an amelioration explaining why and how this could have happened (Heckmann et al., 2013). The ambitious ' $C 4$ rice' project aiming at introducing $C 4$ photosynthesis into one of the most important staple foods, rice, is based on such a strategy (http://c4rice.irri.org/). Other more down-to-earth approaches following the improvement of photosynthesis have been successfully performed. Over-expression of the Arabidopsis thaliana Sedoheptulose 1,7-bisphosphatase (SBPase) and/or Fructose 1,6-bisphosphatase (FBPase) as well as ectopic expression of the Synechocystis sp. PCC 6803 inorganic carbon transporter B (ictB) in tobacco led to an increase in photosynthetic performance and in biomass, most pronounced in triple-transgenic plants (Simkin et al., 2015). A similar approach was conducted in 
rice where a bifunctional SBPase/FBPase and the ictB were over-expressed. Here, photosynthetic performance was also increased. However, of the three parameters determining grain yield in rice, i.e., tiller number, filled grains per panicle and grain weight, only tiller number was increased in the double transformant (Gong et al., 2015).

In another approach over-expression of RubisCO activase (Rcase), an enzyme activating RubisCO, had no impact under normal greenhouse conditions. However, under varying light conditions, RubisCO activation was faster in transgenic plants. Moreover, over-expression of a more thermostable Rcase led to a better RubisCO activation under mild heat stress. Photorespiration increases with temperature due to compromised solubilities of $\mathrm{CO}_{2}$ and $\mathrm{O}_{2}$ in water with a decrease in the ratio of solved $\mathrm{CO}_{2}$ over $\mathrm{O}_{2}$. However, interestingly expression of thermostable Rcase seems to be beneficial for thermostability of photosynthesis (Carmo-Silva et al., 2015 and references therein). In an attempt to prevent photorespiration, glycolate dehydrogenase (GlyDH), a chimeric enzyme consisting of the E.coli GlyDH operon enzymes GlcD, E, F, was over-expressed in potato (Nölke et al., 2014) and in the biofuel crop Camelina sativa (Dalal et al., 2015). The results obtained were similar in both cases, potato plants displayed a strong increase in tuber yield, and Camelina sativa an increase in seed weight per plant.

While most approaches to improve source capacity are targeted to enzymatic reactions, another approach might be the modulation of metabolite distribution and thereby alteration of metabolite-dependent regulation. In this respect, the level of cytosolic sugars (especially hexoses) has been suspected to negatively correlate to photosynthetic activity. In an attempt to down regulate cytosolic glucose levels, the tonoplast monosaccharide transporter1 (TMT1) of Arabidopsis was over-expressed in the background of the Arabidopsis tmt1-2 mutant using the strong constitutive 35SCaMV promoter. TMT1 transports hexoses from the cytosol into the vacuole with the effect that these hexoses or products thereof cannot be recognized by the sugar sensing system anymore. Thus, the signal to down-regulate photosynthesis should be missing. This shift in signaling is reflected in the de-regulation of genes known to be regulated by sugar. The chlorophyll a/b binding protein1 (CAB1), known to be sugar-repressed, is higher expressed in over-expressors than in control plants, whereas expression of the sugar-induced nitrate reductase1 (NR1) is down-regulated in TMT1 over-expressors. Moreover, the phloem loading sucrose transporter SUC2 is 
higher expressed in the transgenic plants. Increased seed yield of TMT1 overexpressing plants can thus be explained by a potentially higher photosynthesis and a better phloem loading of resulting sucrose (Wingenter et al., 2010).

To increase sink capacity, apart from the above-mentioned over-expression of metabolite transporters important for tuber starch formation, sucrose synthase activity was enhanced in potato tubers which led to increased levels of tuber starch and dry weight per plant (Baroja-Fernández et al., 2009). Moreover, down-regulation of plastidic adenylate kinase (ADK) of potato led to an increase in adenylates and a concomitant increase in tuber starch and yield (Regierer et al., 2002). Another approach would be to reduce starch turnover in starch-storing crops by downregulating glucan water dikinase (GWD). This had been done in potato before the actual activity of the enzyme had even been discovered and led to an increase in tuber starch content (Lorberth et al., 1998). Apart from potato, recently the protein loading sucrose into storage vacuoles of sugar beet tap roots has been identified (Jung et al., 2015). This TST called protein is a close homolog of the abovementioned TMT1 of Arabidopsis but transports sucrose instead of glucose. Increasing activity of TST would offer the possibility to increase sink capacity of sugar beet and other sugar storing crops.

\section{Next generation food}

In addition to simply increase food availability, food quality comes into the focus of crop breeding. This step in plant advancement was once initiated because of the finding that not only the amount of food but also its ingredients impact health of humans. Accordingly, nowadays, staple food production in developing countries includes strategies for superior nutritious contents of food. So-called (bio-)fortified cultivars of almost all kinds of staple food will be introduced into the market in the next decades to fight malnutrition-borne diseases and early death (http://www.harvestplus.org/). This approach has been pioneered by the efforts undertaken to generate and introduce 'Golden rice' developed to prevent children from blindness and death provoked by a shortage of vitamin A in their diet (Ye et al., 2000). Other examples for food with such an increase in quality are tomato plants with accumulation of health-promoting anthocyanins (Butelli et al., 2008) or cassava plants with increased bioavailable vitamin B6 (Li et al., 2015). 
However, design and development of strategies to feed the world have to take habits and beliefs into consideration that people especially in target areas adhere to. Thus, 'simple' solutions delivered by natural sciences have to be backed up by sociopolitical programs leading to education and enlightenment to advance the most pressing problem, overpopulation of the world. Otherwise, the vicious circle of satisfying the need for more food will only result in even more people and the need for even more food.

\section{Acknowledgements}

The authors are grateful for the funds from the Bill \& Melinda Gates Foundation, Seattle, WA, USA (OPP1113365).

\section{References}

Araki, M., Ishii, T., 2015. Towards social acceptance of plant breeding by genome editing. Trends Plant Sci. 20, 145-149.

Baroja-Fernández, E., Munoz, F.J., Montero, M., Etxeberria, E., Sesma, M.T., Ovecka, M., Bahaji, A., Ezquer, I., Li, J., Prat, S., Pozueta-Romero, J., 2009. Enhancing sucrose synthase activity in transgenic potato (Solanum tuberosum L.) tubers results in increased levels of starch, ADPglucose and UDPglucose and total yield. Plant Cell. Physiol. 50, 1651-1652.

Beadle, G.W., 1980. The ancestry of corn. Scient. Americ. 242, 112-119.

Boch, J., Scholze, H., Schornack, S., Landgraf, A., Hahn, S., Kay, S., Lahaye, T., Nickstadt, A., Bonas, U., 2009. Breaking the code of DNA binding specificity of TALtype III effectors. Science 326, 1509-1512.

Bortesi, L., Fischer, R., 2015. The CRISPR/Cas9 system for plant genome editing and beyond. Biotechnol. Adv. 33, 41-52.

Breseghello, F., 2013. Traditional and modern plant breeding methods with examples in rice (Oryza sativa L.). J. Agric. Food Chem. 61, 8277-8286.

Butelli, E., Titta, L., Giorgio, M., Mock, H.P., Matros, A., Peterek, S., Schijlen, E.G., Hall, R.D., Bovy, A.G., Luo, J., Martin, C., 2008. Enrichment of tomato fruit with health-promoting anthocyanins by expression of select transcription factors. Nat. Biotechnol. 26, 1301-1308.

Cardi, T., 2016. Cisgenesis and genome editing: combining concepts and efforts for a smarter use of genetic resources in crop breeding. Plant Breeding 135, 139-147. 
Carmo-Silva, E., Scales, J.C., Madgwick, P.J., Parry, M.A.J., 2015. Optimizing Rubisco and its regulation for greater resource use efficiency. Plant Cell Environ. 38, 1817-1832.

Christian, M., Cermak, T., Doyle, E.L., Schmidt, C., Zhang, F., Hummel, A., Bogdanove, A.J., Voytas, D.F., 2010. Targeting DNA double-strand breaks with TAL effector nucleases. Genetics 186, 757-761.

Cullen, J.J., 2001. Plankton: Primary production methods, in Encyclopedia of the Ocean Sciences, ed. J. Steele, S. Thorpe, K. Turekian, pp. 2277-2284, Academic, San Diego.

Daboussi, F., Stoddard, T.J., Zhang, F., 2015. Engineering meganucleases for precise plant genome modification, in Advances in new technology for targeted modification of plant genomes, F. Zhang et al. (eds.), 21-38.

Dalal, J., Lopez, H., Vasani, N.B., Hu, Z., Swift, J.E., Yalamanchili, R., Dvora, M., Lin, X., Xie, D., Qu, R. Sederoff, H.W., 2015. A photorespiratory bypass increases plant growth and seed yield in biofuel crop Camelina sativa. Biotechnol. Biofuels 8, 175.

Davis, G.P., Docchio, M.J., Hetzel, D.J.S., 1997. Smart breeding: selection with markers and advanced reproductive technologies. Proc. Adv. Anim. Breed. Gen. 12, 429-432.

Doebley, J., 2004. The genetics of maize evolution. Annu. Rev. Genet. 38, 37-59.

El-Sharkawy, M.A., 2004. Cassava biology and physiology. Plant Mol. Biol. 56, 481501.

EPA, 2010, Methane and nitrous oxide emissions from natural resources. U.S. Environmental Protection Agency, Washington, DC, USA.

Everson, R.E., Golin, D., 2003. Assessing the impact of the Green Revolution, 1960 -2000. Science 300, 758-762.

Gnan, S., Priest, A., Kover, P.X., 2014. The genetic basis of natural variation in seed size and seed number and their trade-off using Arabidopsis thaliana MAGIC lines. Genetics 198, 1751-1758.

Gong, H.Y., Li, Y., Fang, G., Hu, D.H., Jin, W.B., 2015. Transgenic rice expressing ictB and FBPase/SBPase derived from cyanobacteria exhibits enhanced photosynthesis and mesophyll conductance to $\mathrm{CO}_{2}$. PLoS ONE 10, e0140928.

Hahn, S.K., Reynolds, N., Egbunike, G.N., 1992. Cassava as livestock feed in Africa: Proceedings of the IITA/ILCA/University of Ibadan workshop on the potential utilization of cassava as livestock feed in Africa: 14-18 November 1988, Ibadan, Nigeria.

Heckmann, D., Schulze, S., Denton, A., Gowik, U., Westhoff, P., Weber, A.P.M., Lercher, M.J., 2013. Predicting C4 photosynthesis evolution: Modular, individually adaptive steps on a Mount Fuji fitness landscape. Cell 153, 1579-1588. 
Ho, L.C., 1988. Metabolism and compartmentation of imported sugars in sink organs in relation to sink strength. Ann. Rev. Plant Physiol. Plant Mol. Biol. 39, 355-378.

Huang, S., Weigel, D., Beachy, R.N., Li, J., 2016. A proposed regulatory framework for genome-edited crops. Nat. Gen. 48, 109-111.

International Wheat Genome Sequencing Consortium (IWGSC), 2014. A chromosome-based draft sequence of the hexaploid bread wheat (Triticum aestivum) genome. Science 345, 1251788.

Jinek, M., Chylinski, K., Fonfara, I., Hauer, M., Doudna, J.A., Charpentier, E., 2012. A programmable dual-RNA-guided DNA endonuclease in adaptive bacterial immunity. Science 337, 816-821.

Jonik, C., Sonnewald, U., Hajirezaei, M.R., Flügge, U.I., Ludewig, F., 2012. Simultaneous boosting of source and sink capacities doubles tuber starch yield of potato plants. Plant Biotechnol. J. 10, 1088-1098.

Jung, B., Ludewig, F., Schulz, A., Meißner, G., Wöstefeld, N., Flügge, U.I., Pommerrenig, B., Wirsching, P., Sauer, N., Koch, W., Sommer, F., Mühlhaus, T., Schroda, M., Cuin, T.A., Graus, D., Marten, I., Hedrich, R., Neuhaus, H.E., 2015. Identification of the transporter responsible for sucrose accumulation in sugar beet taproots. Nat. Plants 1, 14001.

Kaimowitz, D., Mertens, B., Wunder, S., Pacheco, P., 2004. Hamburger connection fuels Amazon destruction: Cattle ranching and deforestation in Brazil's Amazon. Center for International Forestry Research, Jakarta, Indonesia.

Kammerer, B., Fischer, K., Hilpert, B., Schubert, S., Gutensohn, M., Weber, A., Flügge, U.I., 1998. Molecular characterization of a carbon transporter in plastids from heterotrophic tissues: the glucose 6-phosphate/phosphate antiporter. Plant Cell 10, 105-117.

Kampfenkel, K., Möhlmann, T., Batz, O., Van Montagu, M., Inze, D., Neuhaus, H.E., 1995. Molecular characterization of an Arabidopsis thaliana cDNA encoding a novel putative adenylate translocator of higher plants. FEBS Lett. 374, 351-355.

Kim, Y.G., Cha, J., Chandrasegaran, S., 1996. Hybrid restriction enzymes: zinc finger fusions to Fokl cleavage domain. Proc. Natl. Acad. Sci. USA 93, 1156-1160.

Kinealy, C., 1994. This great calamity. Gill \& Macmillan.

Kumar, V., Jain, M., 2015. The CRISPR-Cas system for plant genome editing: advances and opportunities. J. Exp. Bot. 66, 47-57.

Li, W., Gill, B.S., 2006. Multiple genetic pathways for seed shattering in the grasses. Funct. Integr. Genomics 6, 300-309.

Li, K.T., Moulin, M., Mangel, N., Albersen, M., Verhoeven-Duif, N.M., Ma, Q., Zhang, P., Fitzpatrick, T.B., Gruissem, W., Vanderschuren, H., 2015. Increased bioavailable 
vitamin B6 in field-grown transgenic cassava for dietary sufficiency. Nat. Biotechnol. 33, 1029-1032.

Lorberth, R., Ritte, G., Willmitzer, L., Kossmann, J., 1998. Inhibition of a starchgranule-bound protein leads to modified starch and repression of cold sweetening. Nat. Biotechnol. 16, 473-477.

Lusser, M., Parisi, C., Plan, D., Rodriguez-Cerezo, E., 2011. New plant breeding techniques - State-of-the-art and prospects for commercial development. JRC Sientific and Technical Reports.

Mendel, G., 1866. Versuche über Pflanzenhybriden. In 'Verhandlungen des Naturforschenden Vereins zu Brünn' 4, 3-47.

Nölke, G., Houdelet, M., Kreuzaler, F., Peterhänsel, C., Schillberg, S., 2014. The expression of a recombinant glycolate dehydrogenase polyprotein in potato (Solanum tuberosum) plastids strongly enhances photosynthesis and tuber yield. Plant Biotechnol. J. 12, 734-742.

Peng, J., Richards, D.E., Hartley, N.M., Murphy, G.P., Devos, K.M., Flintham, J.E., Beales, J., Fish, L.J., Worland, A.J., Pelica, F., Sudhakar, D., Christou, P., Snape, J.W., Gale, M.D., Harberd, N.P. 'Green revolution' genes encode mutant gibberellin response modulators. Nature 400, 256-261.

Petolino, J.F., 2015. Genome editing in plants via designed zinc finger nucleases. In Vitro Cell. Dev. Biol. Plant 51, 1-8.

Pimentel, D., Pimentel, M., 2003. Sustainability of meat-based and plant-based diets and the environment. Am. J. Clin. Nutr. 78 (suppl.), 660S-663S.

Pimentel, D., Burgess, M., 2013. Soil erosion threatens food production. Agriculture 3, 443-463.

Regierer, B., Fernie, A.R., Springer, F., Perez-Melis, A., Leisse, A., Koehl, K., Willmitzer, L., Geigenberger, P., Kossmann, J., 2002. Starch content and yield increase as a result of altering adenylate pools in transgenic plants. Nat. Biotechnol. 20, 1256-1260.

Rocha-Sosa, M., Sonnewald, U., Frommer, W., Stratmann, M., Schell, J., Willmitzer, L., 1989. Both developmental and metabolic signals activate the promoter of a class-I patatin gene. EMBO J. 8, 23-29.

Sage, R.F., Christin, P.A., Edwards, E.J., 2011. The C4 plant lineages of planet earth. J. Exp. Bot. 62, 3155-3169.

Schnable, P.S., Wise, R.P., 1998. The molecular basis of cytoplasmic male sterility. Trends Plant Sci. 3, 175-180.

Shull, G.H., 1908. The composition of a field of maize. Rep. Americ. Breeders Assoc. 4, 296-301. 
Simkin, A.J., McAusland, L., Headland, L.R., Lawson, T., Raines, C.A., 2015. Multigene manipulation of photosynthetic carbon assimilation increases $\mathrm{CO}_{2}$ fixation and biomass yield in tobacco. J. Exp. Bot. 66, 4075-4090.

Sinclair, T.R. and de Wit, C.T., 1976. Analysis of the carbon and nitrogen limitations to soybean yield. Agron. J. 68, 319-324.

Stewart, W.M., Dibb. D.W., Johnston, A.E., Smyth, T.J., 2005. The contribution of commercial fertilizer nutrients to food production. Agron. J. 97, 1-6.

Tanksley, S.D., McCouch, S.R., 1997. Seed banks and molecular maps: Unlocking genetic potential from the wild. Science 277, 1063-1066.

Tilman, D., Fargione, J., Wolff, B., D’Antonio, C., Dobson, A., Howarth, R., Schindler, D., Schlesinger, W.H., Simberloff, D., Swackhamer, D., 2001. Forecasting agriculturally driven global environmental change. Science 292, 281-284.

Tilman, D., Cassman, K.G., Matson, P.A., Naylor, R., Polasky, S., 2002. Agricultural sustainability and intensive production practices. Nature 418, 671-677.

Turgeon, R., 1989. The sink-source transition in leaves. Ann. Rev. Plant Physiol. Plant Mol. Biol. 40, 119-138.

United Nations, Department of Economic and Social Affairs, Population Division, 2015. World population prospects: The 2015 revision, key findings and advance tables. Working paper No. ESA/P/WP.241.

Verhoeven, J.T.A., Setter, T.L., 2010. Agricultural use of wetlands: opportunities and limitations. Ann. Bot. 105, 155-163.

Wingenter, K., Schulz, A., Wormit, A., Wic, S., Trentmann, O., Hoermiller, I.I., Heyer, A.G., Marten, I., Hedrich, R., Neuhaus, H.E., 2010. Increased activity of the vacuolar monosaccharide transporter TMT1 alters cellular sugar partitioning, sugar signaling, and seed yield in Arabidopsis. Plant Physiol. 154, 665-677.

Ye, X., Al-Babili, S., Klöti, A., Zhang, J., Lucca, P., Beyer, P., Potrykus, I., 2000. Engineering the provitamin A (beta-carotene) biosynthetic pathway into (carotenoidfree) rice endosperm. Science 287, 303-305.

Zhang, L., Häusler, R.E., Greiten, C., Hajirezaei, M.R., Haferkamp, I., Neuhaus, H.E., Flügge, U.I., Ludewig, F., 2008. Overriding the co-limiting import of carbon and energy into tuber amyloplasts increases the starch content and yield of transgenic potato plants. Plant Biotechnol. J. 6, 453-464.

Zhang, L., Garneau, M.G., Majumdar, R., Grant, J., Tegeder, M., 2015. Improvement of pea biomass and seed productivity by simultaneous increase of phloem and embryo loading with amino acids. Plant J. 81, 134-146.

\section{Figure legends}


Figure 1: Negative impact of food production and strategies to minimize environmental consequences

Figure 2: Source-to-sink relations are not static but under developmental and environmental control. A, vegetative growth phase; B, generative growth phase; C, environmental stress leading to defence responses

Figure 3: Possible strategies to improve crop productivity by manipulating source-tosink relations, here depicted for a starch-storing crop. The principle is also valid for crops storing other substances like oil, sugar or protein. 

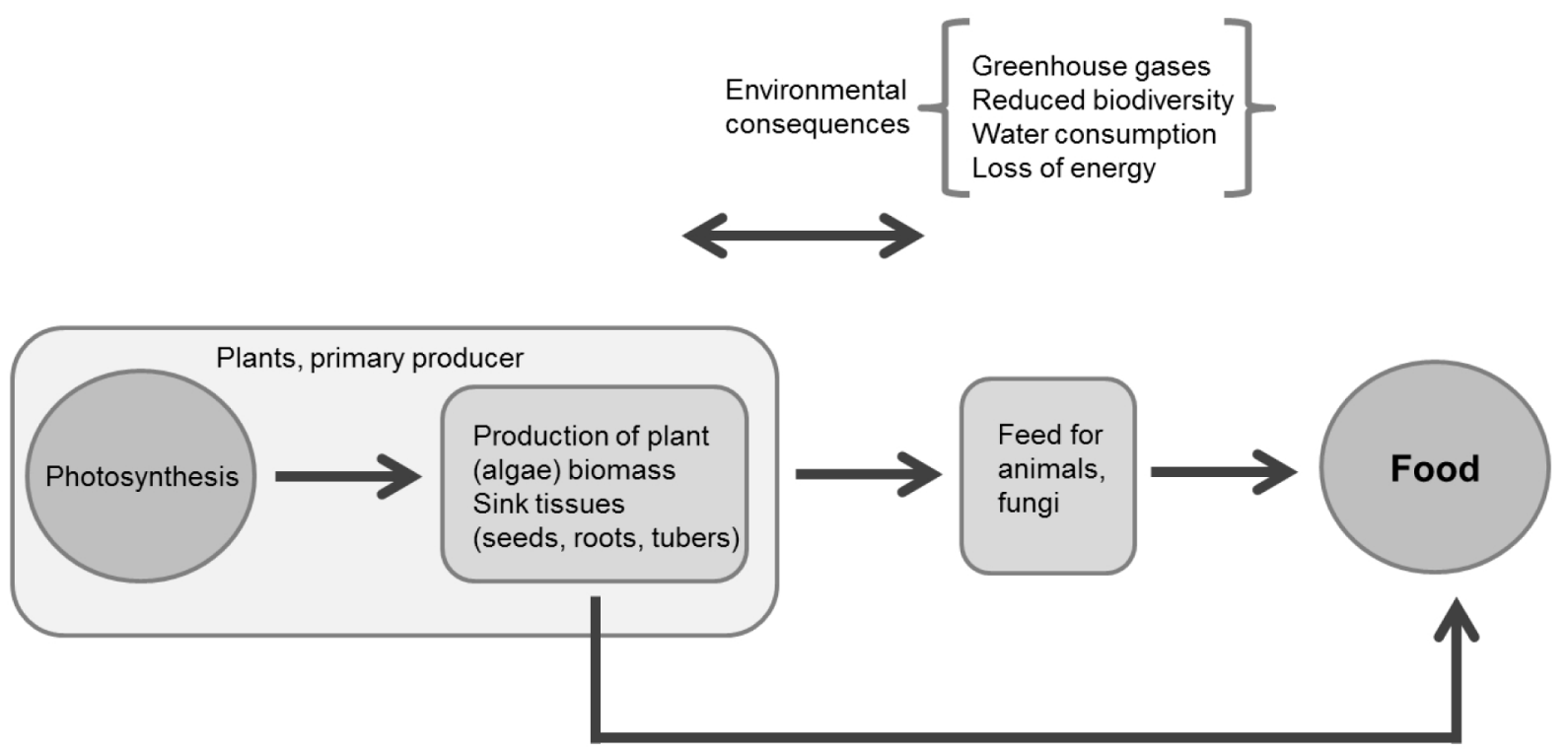

Figure 1: Negative impact of food production and strategies to minimize environmental consequences 
A

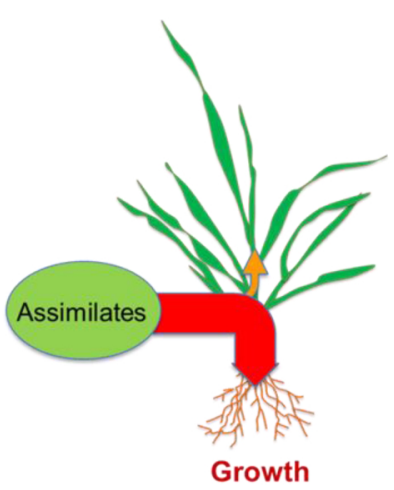

B

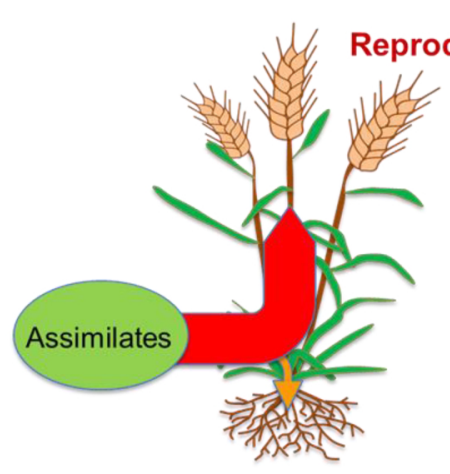

C

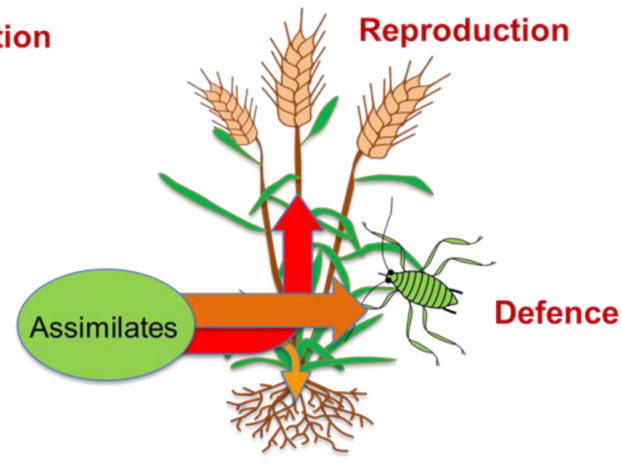

Figure 2: Source-to-sink relations are not static but under developmental and environmental control. A, vegetative growth phase; $B$, generative growth phase; $C$, environmental stress leading to defence responses 
- Improved photosynthesis

- Reduced photorespiration

Push

Production

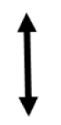

Transport

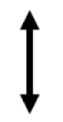

Pull

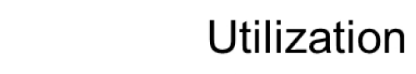

- Improved sucrose availability

- Altered sugar sensing

- Improved allocation to desired sinks

- Accelerated storage organ initiation

- Improved sucrose hydrolysis

- Improved starch accumulation

- Reduced starch breakdown

- Altered signalling

Storage $\longleftrightarrow$ Consumption

Figure 3: Possible strategies to improve crop productivity by manipulating source-to-sink relations, here depicted for a starch-storing crop. The principle is also valid for crops storing other substances like oil, sugar or protein. 